\title{
Spirituality and Religiosity during Suicide Bereavement: A Qualitative Systematic Review
}

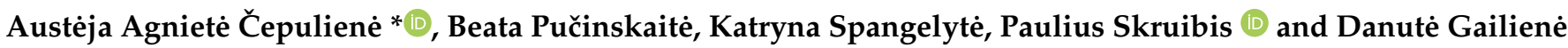 \\ Suicide Research Centre, Institute of Psychology, Faculty of Philosophy, Vilnius University, 01513 Vilnius, \\ Lithuania; beata.pucinskaite@fsf.stud.vu.lt (B.P.); katryna.spangelyte@fsf.stud.vu.lt (K.S.); \\ paulius.skruibis@fsf.vu.lt (P.S.); danute.gailiene@fsf.vu.lt (D.G.) \\ * Correspondence: austeja.cepuliene@fsf.vu.lt
}

Citation: Čepulienè, Austëja Agnietè, Beata Pučinskaitè, Katryna Spangelytè, Paulius Skruibis, and Danutè Gailienè. 2021. Spirituality and Religiosity during Suicide Bereavement: A Qualitative Systematic Review. Religions 12: 766. https://doi.org/10.3390/rel12090766

Academic Editor: Curtis Lehmann

Received: 5 August 2021

Accepted: 10 September 2021

Published: 15 September 2021

Publisher's Note: MDPI stays neutral with regard to jurisdictional claims in published maps and institutional affiliations.

Copyright: (c) 2021 by the authors. Licensee MDPI, Basel, Switzerland. This article is an open access article distributed under the terms and conditions of the Creative Commons Attribution (CC BY) license (https:// creativecommons.org/licenses/by/ $4.0 /)$.

\begin{abstract}
A loved one's loss to suicide can be a traumatic experience and trigger a difficult grief process, identity changes, a loss of the sense of meaning and a spiritual crisis. Spirituality and/or religiosity $(\mathrm{S} / \mathrm{R})$ can be both an important resource and a source of stigmatisation during suicide bereavement. This study aims to synthesise the extant findings about $S / R$ during suicide bereavement in qualitative studies. After an exhaustive selection of articles, the current review utilised a total of 484 citations and seven studies. A thematic synthesis yielded five major themes related to S/R during suicide bereavement: the need to be helped by the religious community without being judged; S/R-related experience of the deceased as a figure who continues to exist; S/R experienced without a conscious choice; conscious reach towards S/R themes; not relating to S/R during suicide bereavement. These findings indicate that the role of $S / R$ during suicide bereavement is complex and varies from providing help to serving as a source of suffering. Hence, practitioners and religious communities should be mindful of the $S / R$ themes during suicide bereavement.
\end{abstract}

Keywords: spirituality; religiosity; suicide bereavement; stigmatisation

\section{Introduction}

Around 800,000 people die by suicide every year (WHO 2021). One suicide seriously affects 15-30 individuals (Cerel et al. 2014), therefore, every year at least 12,000,000 people lose a loved one to suicide and become suicide survivors. These people experience various challenges when dealing not only with the bereavement process but often also with psychological trauma (Jordan 2001; Honeycutt and Praetorius 2016; Jordan 2017), stigmatisation and self-isolation (Pompili et al. 2013; Hanschmidt et al. 2016). A person's spiritual dimension can be deeply affected after a loved one's suicide in ways that might influence the trajectory of the bereavement process. Spirituality and/or religiosity (S/R) can serve as an important resource during suicide bereavement. However, S/R can also be a source of stigmatisation in this process (Krysinska et al. 2017).

A loved one's death, grief and bereavement usually provoke questions and thoughts about the meaning of death and life, the existence of an afterlife and other kinds of themes related with $S / R$. For example, in an analysis of randomly selected online memorials, 14 percent of the memorials written by suicide survivors had content related to $S / R$ themes (Krysinska et al. 2014). Research also suggests that people bereaved by suicide sometimes tend to search for help and relief in rituals and prayers (Vandecreek and Mottram 2009; Castelli Dransart 2018). They start to engage in spiritual or religious practices even if before the loss they did not think about themselves as spiritual or religious (Castelli Dransart 2018). On the other hand, previously religious people sometimes experience a spiritual crisis after a loved one's suicide, which involves doubts about trusting the benevolent God or believing in a purposeful and meaningful life (Lynn Gall et al. 2015; Castelli Dransart 2018). Religious people sometimes isolate themselves from their social networks because of feelings of shame and suicide-related stigmatisation that ensues from religious doctrines 
(Vandecreek and Mottram 2009; Mastrocinque et al. 2018). To sum up, S/R might play different roles during suicide bereavement and should be explored to develop a holistic picture of the bereavement process after suicide.

Despite the scarcity of research focused specifically on spirituality or religiosity during suicide bereavement (Krysinska et al. 2017), S/R-related themes seem to emerge in studies about suicide survivors. We see this scarcity as a gap in suicidology literature and an opportunity to expand our knowledge about the process of bereavement after suicide. To introduce the subject and aim of the current review, we will first describe difficulties related to bereavement after suicide; second, we will define the concepts of spirituality and religiosity and how they can impact the bereavement process; third, we will explain the rationale for a systematic review of qualitative studies on suicide bereavement and spirituality/religiosity.

\subsection{Bereavement after Suicide}

Bereavement is a difficult, painful but normal part of almost every human life (Andriessen et al. 2019). However, a loved one's loss to suicide is not a usual kind of loss and bereavement after suicide is often a profoundly painful and difficult experience. Individuals bereaved by suicide loss experience a variety of reactions to the loss, of which some are common grief reactions and others are specific suicide bereavement reactions. For example, suicide survivors can feel grief, sadness, anger, denial, longing, blame and guilt, they can experience a tiring question of "why" related to the cause of death (e.g., why did the suicide happen, what could I have done to prevent it? etc.) (Jordan 2001, 2017; Jordan and McGann 2017). The grief can be mixed with traumatic reactions (Jordan 2001), which emerge as intrusive thoughts and dreams about the deceased, fear of death and of suicide, avoidance of stimuli related to the loved one and his or her death, irritation and anger (Bellini et al. 2018). Suicide loss might be a risk factor for prolonged grief disorder (Linde et al. 2017; Bellini et al. 2018), posttraumatic stress disorder, major depression, anxiety disorders (Bellini et al. 2018; Andriessen et al. 2019), as well as somatic diseases compared with people bereaved after a loved one's non-suicidal death and compared with people bereaved after other kinds of violent or unexpected death (Spillane et al. 2017). Suicide survivors might have disturbed and distanced social relationships later in life (Andriessen et al. 2019), worse psychological well-being and worse quality of life when compared with people who have not experienced a loved one's suicide (Erlangsen et al. 2017). Eventually, experiencing a loss by suicide increases the chances that the bereaved person will develop suicidal thoughts or even die by suicide themselves (Agerbo 2005; Young et al. 2012; Maple et al. 2017). The variety of difficulties related to suicide bereavement challenges researchers and practitioners to find ways to ease, at least a little, the psychological suffering after a loved one's suicide.

With regard to the social environment, suicide survivors often experience stigmatisation from other people and community members. The topic of suicide, the cause of death and the suicide survivor's grief experience are usually surrounded by silence (Farberow et al. 1992; Pompili et al. 2013). The stigma is sometimes projected onto others by the survivor themselves (Pompili et al. 2013; Sheehan et al. 2018). The fear of being judged and shunned by society can be followed by the survivor's social isolation (Pompili et al. 2013; Hanschmidt et al. 2016), which can harden the grief process (Peters et al. 2016) and even contribute to the survivor's higher suicide risk (Oexle et al. 2020). Stigmatisation after suicide is more common compared with other types of loss (Hanschmidt et al. 2016) and might be a specific component of the bereavement process after suicide. The stigma of suicide might be rooted in collective views and attitudes towards suicide sometimes related to religious beliefs, and in the fear of talking about something that is extremely uncomfortable.

Despite of all the issues that might exist during suicide bereavement, the ever developing, processing and adjusting nature of the human being usually impacts the bereavement process. By this, we mean that the feelings and components of grief are dynamic and 
tend to change with time both qualitatively and quantitatively. The newest grief theories and grief research indicate that the process of bereavement may never end. The loss of a loved one changes the person irreversibly. Indeed, this loss must be integrated into the individual's ongoing life (Jordan and McGann 2017) and in this process the person faces the need to draw meaning from the loss (Neimeyer et al. 2006) as well as to transform and hold on to the continuing bond with the deceased (Klass and Steffen 2018). This might happen via the dual process model, which consists of interchangeably focusing on the loss and stepping back from focusing on it (Stroebe et al. 2010). It must be noted that loss due to suicide can make these processes more difficult. For example, suicide survivors might have less positive continuing bonds with the deceased loved one than those who lose somebody to other causes because of the anger towards the loved one and the feeling of being left alone. The less positive continuing bonds lessen the possibilities for post-traumatic growth in people bereaved by suicide (Levi-Belz 2017). All in all, this short overview of studies on grief reveals the complexity of the bereavement process, which gets even more complicated when the cause of death is suicide.

In conclusion, suicide bereavement can be different from bereavement after other types of loss and involves specific issues that should be considered when researching these questions and helping suicide survivors. Suicide is a major issue for the health system, but it can be prevented (WHO 2021). Although suicides present a myriad of problems, they continue to happen and affect large numbers of people who are left to deal with their grief and psychological pain. Therefore, researchers and practitioners should seek to better understand the experiences of suicide survivors and find ways to help them integrate the loss into their lives.

\subsection{Spirituality and Religiosity}

Spirituality and religiosity (S/R) have lots of definitions and are usually seen as abstract concepts that are difficult to research. The field of suicidology might only be at the start of including spirituality and religiosity-related themes into its research, although $S / R$ in the process of suicide and in bereavement after suicide is seen by some authors as a very important and potentially preventive resource (Colucci 2008; Krysinska et al. 2017; Castelli Dransart 2018).

In the current review, we define spirituality as a search for the domain of the sacred (Pargament 2007) and, in line with the analytical psychology approach, as seeking a sensitive, contemplative and transformative relationship with the Sacred (Tacey 2004). The domain of the Sacred refers to those aspects of life that represent divinity for a particular individual (for example, God, the Higher Power, the Mysterious Other, the Universe, the transcendental realm, connectedness to nature, music and even relationships). The search refers to the human potential to contemplate and actively search for connectedness to the domain of the Sacred via thoughts, beliefs, rituals, virtues, feelings, experiences and other ways (Pargament 2007; Pargament and Lomax 2013). Religion can be one of the ways to search for the domain of the Sacred and religiosity refers to following the religion's path, rituals, rules, virtues, and doctrines with the goal to connect with the Sacred (Pargament and Lomax 2013). The spiritual potential to search for the Sacred can also be viewed as a universal human need (Jung [1938] 1960). Spiritual needs might have to be satisfied regularly and coherently, and the means to satisfy the need must fit to the particular individual and their culture (Jung [1938] 1960; Tacey 2004). The culture the individual lives in usually provides the means, such as religion, to satisfy spiritual needs, but with the processes of secularisation, the cultural means can become a departure from the subjective spiritual needs of a person (Tacey 2004). To avoid theoretical misunderstandings, for the current review we chose to use the terms of spirituality and religiosity together, shortened to 'S/R'. We use the terms that define divinity (like God, the Higher Power, Mysterious Other, etc.) interchangeably.

After defining $S / R$, an explanation of the $S / R$ experience is warranted. The $S / R$ experience in the current paper refers to the experiential part of spirituality, which is usually 
borne as a deep feeling of connectedness that might not yield itself to a rational mind, for example, with 'something bigger', God or the Universe (Tacey 2004; Pargament 2007), or even the soul of the deceased loved one (Jahn and Spencer-Thomas 2014; Krysinska et al. 2017). The term 'the sense of presence' describes sensory impressions of the presence of the deceased (Jahn and Spencer-Thomas 2014). The experiential part of spirituality can also be experienced as strong emotional reactions or feelings that are felt as if coming from the outside (sometimes, as coming from the Higher Power or God), such as grace, gratitude, compassion, meaningfulness, belongingness, hope and connectedness with other people (Pargament 2007). We emphasise the experiential part of $S / R$ with the intention to deepen the understanding of psychological aspects of $S / R$ experiences without specifying whether these experiences are coming from a mystical power, psychological mechanisms, or the unconscious.

\subsection{S/R during Bereavement}

When a person encounters, usually unwillingly, the phenomena of death and temporality of life, the potential to search for the Sacred might be triggered regardless of the person's previous beliefs, practices, religion or spirituality (Kast 1993; Castelli Dransart 2018; Stelzer et al. 2020). The Sacred usually refers to hope for eternity, which contradicts the instinctive fear of death. $S / R$ can also relate to finding (or searching for) meaning in life and death (Wortmann and Park 2008), answering questions about the afterlife (Vandecreek and Mottram 2009) and transforming the bond with the deceased (Sas and Coman 2016; Castelli Dransart 2018), providing means to calm down, pray or meditate (Lynn Gall et al. 2015), solving responsibility questions (Mastrocinque et al. 2018) and belonging to a spiritual or religious community, which can offer practical, spiritual, emotional support and friendships (Vandecreek and Mottram 2009). When facing death, S/R provide answers and means to deal with the uncontrollable.

Systematic reviews of studies on $S / R$ and bereavement have identified $S / R$ as a potential resource in coping with the loss of a loved one (Becker et al. 2007; Wortmann and Park 2008; Hai et al. 2018), although authors note the limited number of these studies and questionable research methods in some of them. Because of the multidimensional nature of $S / R$, scientific literature currently does not provide answers and explanations about how different dimensions of $S / R$ interact with the bereavement process. For example, it is almost clear that religious affiliation does not suffice to adjust to bereavement (Wortmann and Park 2008), and there are also findings suggesting that personal religiosity without communal religiosity might result in negative religious coping (Stelzer et al. 2020). Altogether, $S / R$ during bereavement might have an important role for the different aspects of the bereavement process, but since these constructs are so complex they must be measured carefully and researched using methods that do not reduce their essence.

The small number of studies on $S / R$ and suicide bereavement indicate that belief in the afterlife with the hope to reunite with the deceased person can help the bereavement process (Lichtenthal et al. 2013), but S/R may not always help with the process of meaning making (Murphy and Johnson 2003). Suicide survivors might engage in positive spiritual/religious coping, which might alleviate suffering during bereavement (Krysinska et al. 2017). Spiritual experiences are common among suicide survivors (Jahn and SpencerThomas 2014, 2018; Krysinska et al. 2017) and can facilitate belief in the afterlife, hope to reunite with the deceased person and continue bonds (Jahn and Spencer-Thomas 2014). $\mathrm{S} / \mathrm{R}$ might be a potential resource during suicide bereavement, but it is not very clear which aspects and qualities of $S / R$ are important.

However, the loss of a loved one to suicide can trigger a spiritual crisis (Castelli Dransart 2018), loss of faith (Lynn Gall et al. 2015), a need to revise previous beliefs and virtues (Lynn Gall et al. 2015), problems with forgiving God for the suicide (Castelli Dransart 2018) or questions about the responsibility and involvement of God in the act of suicide (Vandecreek and Mottram 2009; Krysinska et al. 2014; Castelli Dransart 2018). Another difficulty might come from the views and attitudes of religious and spiritual 
communities towards suicide, which sometimes might be stigmatising and judge the deceased and the bereaved (Vandecreek and Mottram 2009; Castelli Dransart 2018). Besides, the behaviour of the clergy with suicide survivors might not always be informed by psychological knowledge about the bereavement process after suicide or about suicide itself (Castelli Dransart 2018; Mastrocinque et al. 2018) and encounters with stigmatising views might deepen the sadness, anger, and disappointment during the process of bereavement. Lastly, a personal spiritual crisis might give rise to various questions and issues related to bereavement.

Overall, we find that $S / R$ is a dimension paramount in the context of suicide bereavement. S/R might function both as a valuable resource and an obstacle during the bereavement process. It can function via many forms and manifestations, such as personal beliefs, thoughts, dreams and experiences as well as via connection to religious communities and during funeral services or farewell rituals. Little is understood about how people bereaved by suicide experience $S / R$, connect to the deceased or even what they think about S/R during suicide bereavement (Krysinska et al. 2017; Castelli Dransart 2018). These questions are important not only for a deeper understanding of the bereavement process after suicide but also to help people bereaved by suicide fulfil the spiritual needs that arise after a loved one's suicide (Tacey 2004).

\subsection{Aims of the Current Study}

The quantitative studies cited above reveal separate aspects of $S / R$ manifest during suicide bereavement, yet they do not reflect the complex nature of bereavement and $\mathrm{S} / \mathrm{R}$. When certain questions do not yield themselves to quantitative research methods, qualitative methods may be used. Although less popular and less evolved, the method of systematic review of qualitative studies provides an opportunity to gather the existing findings from qualitative studies about questions which cannot be answered by quantitative methods (Thomas and Harden 2008; Saini and Shlonsky 2012). The whole thematic content of the experiences of those bereaved by suicide cannot be captured by quantitative research (Jordan 2001; Shields et al. 2017). If we want not to explore the correlates but to gain an indepth understanding of idiosyncratic experiences of people bereaved by suicide, we need to concentrate on qualitative research (Hjelmeland and Knizek 2010). We are interested in understanding manifestations of $S / R$ during the process of grief after suicide. Given the importance of understanding the thematic content of the relevant processes and the fact that the phenomenon of $\mathrm{S} / \mathrm{R}$ in bereavement after suicide is relatively under-researched, the current review will focus on qualitative studies specifically exploring $S / R$ and suicide bereavement.

We are aware that the themes of $S / R$ can emerge in suicide bereavement research "accidentally", but in order to provide a more thorough understanding of the S/R phenomenon, we will restrict ourselves to articles with a specific focus on $S / R$ and not on other themes of bereavement after suicide. Therefore, the current review aims to explore, synthesise, and analyse the emergent themes related to spirituality and religiosity during suicide bereavement in all accessible qualitative studies.

\section{Materials and Methods}

A search of three databases (Medline, PsychINFO and Web of Science) was carried out using a range of keywords related to suicide, bereavement, spirituality, and religiosity. The search included journals related to medicine (including psychiatry) (Medline), psychology (PsycINFO) and social sciences (Web of Science). These databases were chosen because our research topic includes psychological and psychiatric aspects of bereavement after suicide, whilst spirituality or religiosity is a topic that can be related to the social sciences, religious studies in particular. We searched each database without specifying the time range, which yielded the oldest article from 1975 and the newest from 2020. The search words were "(suicide AND (bereavement OR grief OR loss OR survivor) AND (spiritual ${ }^{*}$ OR religio*))". PsychINFO returned 224 articles, Medline 112, and Web of Science 148. Since PRISMA 
guidelines are not created for systematic reviews of qualitative studies (Page et al. 2021), the study was carried out according to ENTREQ guidelines (Tong et al. 2012).

First, 484 citations were identified (see Table 1). After removal of duplicates, a total of 346 titles and abstracts were analysed and 337 were excluded. Inclusion criteria were original papers reporting qualitative research; peer-reviewed articles; suicide survivors as a study population, regardless of which family member died by suicide; written in English; focus on spirituality and/or religiosity during suicide bereavement. The process of selection and analysis of papers was conducted independently by three reviewers. Their disagreements were solved in discussions until common decisions were reached.

Table 1. Number of citations from the databases.

\begin{tabular}{ccccc}
\hline Database & $\begin{array}{c}\text { Number of Citations } \\
\text { Found }\end{array}$ & $\begin{array}{c}\text { Number of Citations } \\
\text { after Removal of } \\
\text { Duplicates }\end{array}$ & $\begin{array}{c}\text { Number of Citations } \\
\text { after Reviewing Titles } \\
\text { and Abstracts }\end{array}$ & $\begin{array}{c}\text { Number of Articles } \\
\text { after Full-Text } \\
\text { Reading }\end{array}$ \\
\hline PsychInfo & 224 & 223 & 6 & 4 \\
Medline & 112 & 48 & 0 & 0 \\
Web of science & 148 & 75 & 3 & 3 \\
Total: & 484 & 346 & 9 & 7 \\
\hline
\end{tabular}

A total of nine full texts were read and assessed for eligibility. The JBI critical appraisal tool for qualitative research and systematic reviews was used for the assessment of eligibility (JBI 2020). After the assessment, two articles had to be excluded (as one did not utilise qualitative methods and the other did not focus on S/R during suicide bereavement) (see Figure 1).

Assessment of eligibility was conducted independently by three reviewers who reached a common decision to include seven articles for systematic review (see Table 2).

Data extraction (author, year of publication, journal, title, and results) was performed in an Excel sheet. The analysis was conducted in three phases in accordance with Thomas and Harden's (2008) method of thematic synthesis. First, each article was read many times to achieve immersion in the data. Each line of the results section was examined and coded by hand using free line-by-line coding. One randomly selected article was coded by three reviewers independently, then every code was reviewed together and discussed. The other six articles were coded by two reviewers independently and then reviewed together and discussed until common codes were created. Second, descriptive themes were formulated and refined through several meetings of the three reviewers. Finally, analytical themes were developed in order to "reach beyond" the initial results of the reviewed articles. The analytical themes were created through an understanding of the themes in the context of the aims of this review. The entire research team discussed and generated the final set of themes in several meetings. 
Table 2. Studies included in the review.

\begin{tabular}{|c|c|c|c|c|c|c|c|}
\hline $\begin{array}{c}\text { Authors, Year of } \\
\text { Publication, Title and } \\
\text { Journal }\end{array}$ & Country & Methods & Sample Characteristics & $\begin{array}{l}\text { Recruitment } \\
\text { Method }\end{array}$ & Analysis & $\begin{array}{l}\text { Main Findings Related to Suicide Bereavement } \\
\text { and S/R }\end{array}$ & Quality and Limitations \\
\hline $\begin{array}{l}\text { Jahn and Spencer-Thomas } \\
\text { (2018). A Qualitative } \\
\text { Examination of Continuing } \\
\text { Bonds through Spiritual } \\
\text { Experiences in Individuals } \\
\text { Bereaved by Suicide. } \\
\text { Religions. }\end{array}$ & USA & $\begin{array}{l}\text { Demographic and } \\
\text { history questions; } \\
\text { Spiritual Experiences } \\
\text { of Survivors of Suicide } \\
\text { Questionnaire (part of } \\
\text { it, four open-ended } \\
\text { questions) }\end{array}$ & $\begin{array}{l}1301 \text { individuals bereaved by } \\
\text { suicide (1155 female), aged } 40-64 . \\
\text { A total of } 57.9 \% \text { of participants } \\
\text { were affiliated with an organised } \\
\text { religion; a majority ( } 37.4 \%) 482) \\
\text { Protestant Christian, while } 27.2 \% \\
\text { were spiritual but not associated } \\
\text { with an organised religion. }\end{array}$ & $\begin{array}{l}\text { Recruited online } \\
\text { (emails, social } \\
\text { media) }\end{array}$ & $\begin{array}{l}\text { Inductive thematic } \\
\text { approach; thematic } \\
\text { analysis according to } \\
\text { Braun and Clarke }\end{array}$ & $\begin{array}{l}\text { Nine themes about spiritual experiences: a helpful } \\
\text { sense of comfort; a helpful sense of connection } \\
\text { with the deceased; intense sadness evoked by } \\
\text { spiritual experiences; confusion regarding } \\
\text { spiritual experiences; negative reminders of the } \\
\text { deceased or negative meanings of spiritual } \\
\text { experiences; evidence of an afterlife; } \\
\text { general importance of the spiritual experiences' } \\
\text { meaning; impact of and on religious beliefs; and } \\
\text { others' responses to disclosure of suicide or } \\
\text { spiritual experiences. }\end{array}$ & $\begin{array}{l}\text { Generalisation limited by } \\
\text { recruitment methods and } \\
\text { sample characteristics; } \\
\text { method not conducive of } \\
\text { follow-up questions; } \\
\text { failure to include some } \\
\text { S/R related data in the } \\
\text { analysis. }\end{array}$ \\
\hline $\begin{array}{l}\text { Castelli Dransart (2018). } \\
\text { Spiritual and religious } \\
\text { issues in the aftermath of } \\
\text { suicide. Religions. }\end{array}$ & Switzerland & $\begin{array}{l}\text { Face-to-face in-depth } \\
\text { interviews }\end{array}$ & $\begin{array}{c}\text { Data from three studies involving } \\
50 \text { suicide survivors (39 female), } \\
18 \text { survivors younger than } 30 \text {, four } \\
\text { older than } 40 \text {. A total of } 46 \\
\text { participants of Christian origin by } \\
\text { birth (36 Catholics, } 8 \text { Protestants, } \\
\text { and } 2 \text { Evangelists), while } 22 \text { were } \\
\text { "truly Christian", } 17 \text { spiritual, } 10 \\
\text { agnostic or atheist, and } 1 \\
\text { Buddhist. }\end{array}$ & $\begin{array}{l}\text { Recruitment } \\
\text { through social } \\
\text { agencies, self-help } \\
\text { groups, media } \\
\text { advertisements and } \\
\text { snowball sampling }\end{array}$ & Grounded theory & $\begin{array}{l}\text { Four themes/categories: } S / R \text { rites as a resource } \\
\text { for saying farewell and honouring the deceased's } \\
\text { memory; suicide and existence after death; suicide } \\
\text { as a test of spiritual or religious beliefs as well as } \\
\text { of the relationship with transcendence; suicide, } \\
\text { S/R and responsibility. }\end{array}$ & $\begin{array}{l}\text { Studies not focused on } \\
\text { S/R; sample characteristics } \\
\text { not allowing generalisation } \\
\text { and possibly resulting in } \\
\text { biased findings; religiosity } \\
\text { of most participants } \\
\text { possibly hindering } \\
\text { generalisability of findings } \\
\text { to more secular } \\
\text { populations. }\end{array}$ \\
\hline $\begin{array}{l}\text { Lynn Gall et al. (2015). } \\
\text { Spiritual beliefs and } \\
\text { meaning-making within } \\
\text { the context of suicide } \\
\text { bereavement. Juurnal for } \\
\text { the Study of Spirituality }\end{array}$ & Canada & $\begin{array}{l}\text { Semi-structured } \\
\text { interviews }\end{array}$ & $\begin{array}{l}\text { A total of } 11 \text { bereaved individuals } \\
\text { (mean age 49) and four mental } \\
\text { health workers (mean age 53). } \\
\text { Three Catholics, two Protestants, } \\
\text { two Jews and four of no } \\
\text { affiliation. }\end{array}$ & $\begin{array}{l}\text { Recruitment } \\
\text { through support } \\
\text { groups }\end{array}$ & $\begin{array}{l}\text { Phenomenological } \\
\text { approach, method not } \\
\text { specified }\end{array}$ & $\begin{array}{l}\text { Seven themes/categories developed from data } \\
\text { gathered from individuals bereaved after suicide: } \\
\text { impact on spirituality, religious stigmatisation; } \\
\text { religious support; relationship with God; rituals; } \\
\text { afterlife; continued bond. Four themes/categories } \\
\text { developed from data gathered from mental health } \\
\text { workers: involvement of spirituality, afterlife, } \\
\text { rituals, and continued bond. }\end{array}$ & $\begin{array}{l}\text { Sample characteristics not } \\
\text { clearly specified and } \\
\text { limiting generalisation of } \\
\text { findings; limited } \\
\text { information concerning } \\
\text { reflexivity. }\end{array}$ \\
\hline $\begin{array}{l}\text { Krysinska et al. (2014). } \\
\text { Religion and spirituality in } \\
\text { online suicide } \\
\text { bereavement. Crisis }\end{array}$ & $\begin{array}{l}\text { USA, UK, } \\
\text { other } \\
\text { countries }\end{array}$ & $\begin{array}{l}\text { Randomly selected } \\
250 \text { memorials in two } \\
\text { online cemeteries for } \\
\text { the bereaved by } \\
\text { suicide }\end{array}$ & $\begin{array}{l}\text { Thirty-five memorials from } 250 \\
\text { randomly selected memorials } \\
\text { written mostly by family } \\
\text { members on average three years } \\
\text { after the death. }\end{array}$ & $\begin{array}{l}\text { Memorials found in } \\
\text { two online } \\
\text { cemeteries }\end{array}$ & $\begin{array}{c}\text { Interpretative and } \\
\text { deductive thematic } \\
\text { analysis }\end{array}$ & $\begin{array}{l}\text { References to religion/spirituality found in } 14 \% \text { of } \\
\text { memorials. Ten themes: God's will, gratitude for } \\
\text { peace for the deceased, peace wish, continuation of } \\
\text { the spirit/afterlife, reunion, grief of the survivors, } \\
\text { other religious/spiritual, gratitude, description of } \\
\text { the deceased, and general religious/spiritual. }\end{array}$ & $\begin{array}{l}\text { Methodology not allowing } \\
\text { generalisation or deeper } \\
\text { understanding of } S / R \\
\text { during suicide } \\
\text { bereavement. }\end{array}$ \\
\hline $\begin{array}{l}\text { Vandecreek and Mottram } \\
\text { (2009). The religious life } \\
\text { during suicide } \\
\text { bereavement: A } \\
\text { description. Death Studies }\end{array}$ & USA & $\begin{array}{l}\text { Face-to-face } \\
\text { semi-structured } \\
\text { interviews, a } \\
\text { demographic form }\end{array}$ & $\begin{array}{l}\text { Ten women bereaved by suicide, } \\
\text { age from } 48 \text { to } 64(\mathrm{M}=57.5) \text {. Nine } \\
\text { Protestants and one Buddhist. }\end{array}$ & $\begin{array}{l}\text { Recruitment } \\
\text { through suicide } \\
\text { support groups }\end{array}$ & $\begin{array}{l}\text { Qualitative descriptive } \\
\text { analysis }\end{array}$ & $\begin{array}{l}\text { Ten themes: afterlife destiny of the loved one, a } \\
\text { more spiritual perspective, the impact on religious } \\
\text { beliefs, support from family and friends, survivors' } \\
\text { contribution to emotionally distant relationships, } \\
\text { long-term and in-depth spiritual support, } \\
\text { religious support from congregants, the ministry } \\
\text { of clergy, the funeral } \\
\text { service, and the return to public worship services. }\end{array}$ & $\begin{array}{l}\text { Sample characteristics and } \\
\text { recruitment strategy } \\
\text { possibly determining } \\
\text { biased results and } \\
\text { preventing generalisation. }\end{array}$ \\
\hline
\end{tabular}


Table 2. Cont

\begin{tabular}{|c|c|c|c|c|c|c|c|}
\hline $\begin{array}{c}\text { Authors, Year of } \\
\text { Publication, Title and } \\
\text { Journal }\end{array}$ & Country & Methods & Sample Characteristics & $\begin{array}{l}\text { Recruitment } \\
\text { Method }\end{array}$ & Analysis & $\begin{array}{l}\text { Main Findings Related to Suicide Bereavement } \\
\text { and } S / \mathbf{R}\end{array}$ & Quality and Limitations \\
\hline $\begin{array}{l}\text { Vandecreek and Mottram } \\
\text { (2011). The perceived roles } \\
\text { of God during suicide } \\
\text { bereavement. Journal of } \\
\text { Psychology and Theology }\end{array}$ & USA & $\begin{array}{l}\text { Face-to-face } \\
\text { semi-structured } \\
\text { interviews, a } \\
\text { demographic form }\end{array}$ & $\begin{array}{l}10 \text { women bereaved by suicide, } \\
\text { age from } 48 \text { to } 64(\mathrm{M}=57.5), 9 \\
\text { Protestants, } 1 \text { Buddhist. }\end{array}$ & $\begin{array}{l}\text { Recruitment } \\
\text { through suicide } \\
\text { support groups }\end{array}$ & $\begin{array}{c}\text { Descriptive } \\
\text { methodology } \\
\text { (classifying attributions } \\
\text { to God into themes and } \\
\text { describing them) }\end{array}$ & $\begin{array}{l}\text { Four themes: contrary to ancient Christian } \\
\text { teaching, God as judge did not deny heaven to } \\
\text { their loved one; God was in control but was not } \\
\text { responsible for the suicide; God provided } \\
\text { individualised spiritual care; God brought good } \\
\text { out of the tragedy. }\end{array}$ & $\begin{array}{l}\text { Sample characteristics and } \\
\text { recruitment strategy } \\
\text { possibly determining } \\
\text { biased results and } \\
\text { preventing generalisation, } \\
\text { highly religious } \\
\text { participants whose results } \\
\text { may not represent more } \\
\text { secular survivors. }\end{array}$ \\
\hline
\end{tabular}



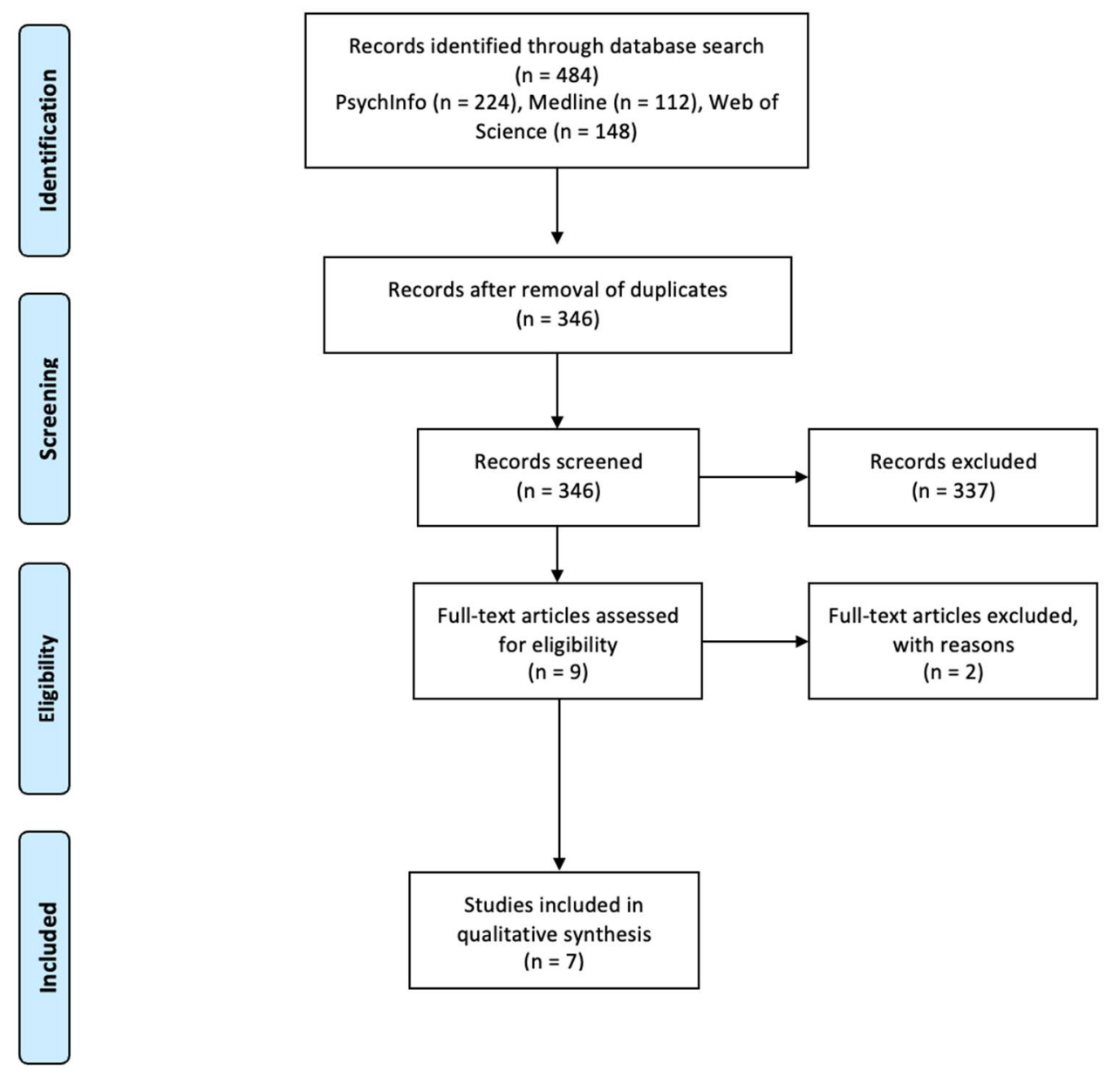

Figure 1. Flow diagram of the database search.

\section{Results}

\subsection{A General Overview}

Most studies were conducted in the USA $(n=4)$, one in the USA, UK, and potentially other countries, one in Canada and one in Switzerland, and the first study was published in 2009. The studies were published in six different journals. Two studies were published in Religions, one in Crisis, one in Death Studies, one in Homicide Studies, one in the Journal of Psychology and Theology, and one in the Journal for the Study of Spirituality. The qualitative methods varied: in two studies the authors used phenomenology, in another two they used qualitative descriptive analysis, one study utilised a framework analysis, one grounded theory and one deductive and interpretative thematic analysis. Regarding data collection, semi-structured face-to-face interviews were used in four studies, focus groups in one study, one study used an online survey with open ended questions and one study utilised online memorials as material for analysis. The samples ranged from 10 to 1301 participants. Regarding the sociodemographic characteristics of the participants, more than half of the studies included both genders $(n=4)$, two studies included only female participants and one study did not provide information about gender. All the participants were adults and, in most cases, family members of the person who died from suicide (except for two studies, which also recruited homicide survivors and mental health workers). Participants ${ }^{\prime}$ religiosity (when indicated) was mostly Christian (Protestant, Roman Catholic, Russian Orthodox), two studies included Buddhist participants, in one study one participant was involved in Wicca, and some participants reported no affiliation. Some participants described themselves as more spiritual than religious (Lynn Gall et al. 2015; Castelli Dransart 2018). Participants were recruited via internet or paper ads, support groups, emails and agencies. One study used online memorials drawn from online cemeteries 
(websites for writing memorials). The main themes or categories identified from the data as well as main the limitations of all seven studies are shown in Table 2.

After applying the thematic synthesis method (Thomas and Harden 2008) for the results of all the studies included in this review, five major themes were identified: the need to be helped by the religious community without being judged; S/R-related experience of the deceased as a figure who continues to exist; $S / R$ experienced without a conscious choice; conscious reach towards $S / R$ themes; not relating to $S / R$ during suicide bereavement. These major themes are not entirely separate and some of them contain the same subthemes (Thomas and Harden 2008). The following sections will cover each theme supported by quotations from the studies included in the review.

\subsection{The Need to Be Helped by the Religious Community without Being Judged}

Suicide survivors, according to the studies reviewed, express a strong need to be helped by members of their religious community in various ways (Vandecreek and Mottram 2009; Lynn Gall et al. 2015; Castelli Dransart 2018; Jahn and Spencer-Thomas 2018; Mastrocinque et al. 2018). The help can be spiritual (related to questions about finding spiritual meaning in grief, answering theological questions about suicide as a sin, restoring the relationship with the Mysterious Other or contemplating the concept of the afterlife), emotional (related to the opportunity to talk to somebody about the loss, the bereavement process and feelings provoked) and/or practical (related to planning and organising the funeral, cleaning the death scene or even bringing food for the suicide survivor the first days after the loss):

"The answer is resoundingly yes. I mean, the minister and people coming over and asking what they could bring and some just showing up and saying, "I'm bringing a pot roast dinner" and just things like that all the time. And hugs always." (Vandecreek and Mottram 2009)

"[t]ook care of everything... I stayed with [friends from the church]. The church had a restoration company in [town] who took all the furniture out of the room, cleaned the room, and replaced the carpet before I went back into the house. The room was repainted, recarpeted before I went back in. The church provided meals. So there was a lot of substantial, tangible support." (Vandecreek and Mottram 2009)

The help can come from parishioners, religious leaders, or the clergy, for example:

"The priest that I dealt with... when we met with him, we said it's important that it not be "I wonder what happened? Who knew this?" I wanted it to be acknowledged, recognised and talked about so that maybe it could help someone else. And he did. You know, he said it was an illness just like cancer or any other illness. So he did, he did a really good job with it." (Mastrocinque et al. 2018)

It is important to notice that helping suicide survivors requires "psychologically informed" attitudes and knowledge about bereavement after suicide:

"Most of my church community responded supportively. A few misunderstood how suicide grief is different than other grief and their well-intentioned attempts at help simply made me feel worse." (Jahn and Spencer-Thomas 2018)

In some cases, the participants shared their need for further help from the clergy: "I would say that [support came] mainly from friends and not so much from the church. It's funny because, initially, I got cards and the minister came over, and all that. But I really think, as much as I adore all those people, I really think that they kind of like dropped the ball because, after that... it was done." (Vandecreek and Mottram 2009)

Help from the religious community can usually be provided during the first days after the death. Funerals and farewell rituals can be a great opportunity to show compassion and respect for the bereaved: 
"When you talk about support, I was astounded at the support. I mean the church was packed with high school kids too, but it was amazing. All the people that came really didn't know us all that well. Her friends and our friends and just a huge support system... It was wonderful." (Vandecreek and Mottram 2009)

Help to plan the funeral service sometimes is not provided because the bereaved people are not religious, which bespeaks the importance of openness of the religious community to non-denominational people:

“...we're non-denominational. I didn't know anything about what kind of arrangements to make and the funeral home had nothing for me." (Mastrocinque et al. 2018)

Other issues regarding funeral planning can stem from different needs and wishes of the loved one's family members and friends (Castelli Dransart 2018), which can harden the already painful and stressful time immediately after the loss:

"He was not a believer, but I still wished to have a mass, I told myself that it wasn't a profession of faith; a burial mass is a prayer, it's those around him who are praying for him (...) the priest told me later that one or two people in the family had said to him: but, after all, he wasn't a believer, why would you bury him with the church and the priest answered: that doesn't stop his close relations from praying for him". (Castelli Dransart 2018)

The need for help is sometimes at odds with the judgmental and stigmatising attitude towards suicide of the religious community (Vandecreek and Mottram 2009; Lynn Gall et al. 2015; Castelli Dransart 2018; Jahn and Spencer-Thomas 2018). If members of the religious community view suicide as a mortal sin or believe that a person who lost a loved one to suicide is a sinner and express their judgmental views, their behaviour is perceived as very hurtful:

"I felt let down by my church community, whose outlook seems to be that anyone who died by suicide or lost a son to suicide must be a sinner[,] have failed to pray enough[,] failed in some way to be a good parent... Not the same as the reaction to a cancer death..." (Jahn and Spencer-Thomas 2018)

It seems that some people actively reach out and share their stigmatising views, which provokes guilt, shame, anger, and sadness in those bereaved by suicide:

"I remember one day a woman came in and she told me that she' $\mathrm{d}$ heard from a friend about this and she said, 'I will pray for her soul because she is probably not going to heaven." (Vandecreek and Mottram 2009)

In addition, suicide survivors sometimes feel confronted with self-stigmatisation. Some of them can be aware of the projections of the stigma to other people, others can project without noticing:

"I think I projected it [shunning] and perceived that people felt that way maybe more than they did. I remember somebody saying something like, "Do you know why he did it?" "Well no." "Were you close?" "Well, I thought so." I don't think those were particular stigmas, but I just felt like people must think I'm the worst mother of the year because [name] killed himself." (Vandecreek and Mottram 2009)

Therefore, the kindness showed by the religious community can function as a cushion against self-stigmatisation and help the bereaved person to overcome the tendency to self-isolate.

Overall, the religious community, even if the bereaved person was not a very active member of it before the loss, can play a very important role in meeting the bereaved person's needs after suicide loss. If community members are well educated about suicide and grief and really want to help, they can support the person immediately after death by praying and being together, helping to plan the funeral, and talking to the bereaved person about religious and spiritual issues. Priests, pastors and religious leaders can 
provide spiritual comfort to the bereaved person, which is needed in their struggles with the meaning of life and death, guilt, the question why and other reactions to the loss. Although Christianity no longer condemns people who die by suicide, stigmatising views of religious communities are still apparent in the studies reviewed and such judgmental beliefs and attitudes leave a hurtful scar in people bereaved by suicide.

\subsection{S/R-Related Experience of the Deceased as a Continuing to Exist Figure}

The deceased can be experienced as an external figure who continues to exist during suicide bereavement. This major theme involves experiences and beliefs about the deceased's existence in the afterlife. People bereaved by suicide tend to express a hope to meet the deceased again in the afterlife (Vandecreek and Mottram 2009; Krysinska et al. 2014; Lynn Gall et al. 2015; Castelli Dransart 2018; Jahn and Spencer-Thomas 2018; Mastrocinque et al. 2018). The hope of the infinite life after death is sometimes based on religious beliefs about the afterlife (usually, Heaven) and sometimes can be unrelated to religious beliefs:

"I still do not believe in God, but at the same time one day I began to say to myself: one day I will see him again." (Castelli Dransart 2018).

The common belief or hope is that the person does not lose their identity after death and reunion with the same and unchanged person will be possible after death. In some cases, the belief about reunion is more abstract-the transcendental realm is called "the garden of spirits" (Krysinska et al. 2014), and sometimes the connection to the deceased is seen as related to the idea of "soul vibration" (Krysinska et al. 2014).

The bereaved wonder and care about the deceased's state in the transcendental realm (Vandecreek and Mottram 2009, 2011; Krysinska et al. 2014; Castelli Dransart 2018; Jahn and Spencer-Thomas 2018; Mastrocinque et al. 2018). Suicide is usually viewed as an unnatural way to die, therefore some suicide survivors fear about the deceased's status in God's eyes and wonder about the process of purification before going to Heaven. Buddhists are concerned about the process of reincarnation, which can be affected by suicide as a cause of death (Vandecreek and Mottram 2009; Castelli Dransart 2018). Lastly, some bereaved people struggle with ancient Christian views about suicide as a mortal sin and must adjust their own beliefs to be sure that God does not deny Heaven for people who die by suicide (Vandecreek and Mottram 2009, 2011; Krysinska et al. 2014; Lynn Gall et al. 2015; Castelli Dransart 2018; Mastrocinque et al. 2018):

"I guess what I believe, and this is totally not in sync with the Orthodox Church... I

don't believe in hell and heaven. I believe there is an afterlife for everybody and it's a good afterlife." (Lynn Gall et al. 2015)

The image of the loved one carried in God's hands or the bereaved putting the deceased into God's hands repeats in multiple studies (Castelli Dransart 2018; Krysinska et al. 2014; Vandecreek and Mottram 2009):

"God saw he was hurting and took him to rest in his arms for eternity." (Krysinska et al. 2014)

Another part of the experience of the deceased as a continuing to exist figure is related to the spiritual connection between the deceased and the bereaved. Such a continuing relationship with the deceased can be vigorous and spontaneously experienced in various ways (Lynn Gall et al. 2015; Castelli Dransart 2018; Jahn and Spencer-Thomas 2018; Mastrocinque et al. 2018). The deceased, according to the participants of the studies reviewed, show up in dreams, through automatic writing, boardgames and coincidences, for example:

"There's a big tree in front of where his gravesite is and one bird showed up, and then another. And by the time I left there were like ten birds in this tree going: Yap, yap, yap, yap! So it was... little signs that... he's OK. And he knows you came, and he's happy you came." (Lynn Gall et al. 2015) 
"I felt like he was writing through me, I wrote in tears and almost in a trance, it was very intense for the first few days, then it gradually faded out over the year." (Castelli Dransart 2018)

The deceased usually communicates that they are relieved from pain and happy in Heaven (Jahn and Spencer-Thomas 2018; Lynn Gall et al. 2015):

"My brother told me he was ok[ay], happy, free from torments of life and in heaven. It made me so happy." (Jahn and Spencer-Thomas 2018)

Sometimes the loved one gives an important message about the bereaved person's life (Jahn and Spencer-Thomas 2018):

"Let me know everything would be [okay]... I would get the job... and I did." ( Jahn and Spencer-Thomas 2018)

The loved one who shows up in some cases allows the bereaved to say goodbye, helps them with grief-related sadness and explains the reasons for their death (Jahn and Spencer-Thomas 2018):

"In my dream he was telling me goodbye and telling me why he had to do it so I found some peace in that but at the same time it made me very sad because he was gone." (Jahn and Spencer-Thomas 2018)

Sometimes experiences of the deceased's presence are perceived as scary and unwanted because of the fear that the deceased is not at peace or because of the sadness provoked (Lynn Gall et al. 2015; Jahn and Spencer-Thomas 2018), for example:

"I think she may be stuck in limbo and unhappy." (Jahn and Spencer-Thomas 2018)

Suicide survivors also share stories about intuitive experiences that occurred during the time of the loved one's suicide (Mastrocinque et al. 2018):

"I felt his soul rise when he died, like a part of me was going up... It was about (time of day) in the morning and I felt it go up. And I could tell it was death..."

(Mastrocinque et al. 2018)

People bereaved by suicide find ways to involve themselves in a relationship with the deceased not only through mediums and third parties (Castelli Dransart 2018; Mastrocinque et al. 2018) but also through personal rituals (funerals, masses, visits to the cemetery, planting trees, lighting candles, smudging, listening to specific music, contemplation), which help them remember and transform the bond with the deceased (Krysinska et al. 2014; Lynn Gall et al. 2015; Castelli Dransart 2018):

"When I have those moments when I'm really missing them... I have a little ritual, which is... [to] light the little angel candle... you know, spiritually wishing them well by lighting the little angel candle. Hoping [my friend's] way gets lit... because if he's stuck in the darkness, then let the little angel light his way." (Lynn Gall et al. 2015)

Specifically, the farewell rituals with their components such as music, common prayers, sermons, traditions and people who attend, are important immediately after the loved one's suicide to say goodbye to the deceased and to start the necessary transformation of the bond with the loved one (Castelli Dransart 2018):

"The Buddhist survivor created a gathering that reflected her tradition and many of her loved one's friends and neighbours attended: [Name] lived in a log house out of town and so we set up these tents and we had bales of straw and I hired a woman to come and play the fiddle, and we had a big chili supper, and [name] was a horseshoer... Eight horseshoeing friends of his came with their horseshoeing vehicles and... they all made him a shoe, a handmade shoe and... they put a bar at the open end so that luck wouldn't run out, and gave it to me." (Vandecreek and Mottram 2009) 
Overall, this major theme signifies that the deceased can be experienced as a figure who continues to exist and that the bereaved can be strongly involved in contemplation about the afterlife of the deceased. The sense of the deceased's presence and communication with the deceased are so commonly reported in studies that this can be viewed as a potentially common experience not specifically related to religious beliefs. Also, the role of farewell and other rituals can be important in finding ways to transform, understand and become consciously involved in the continuing bond with the deceased.

\subsection{S/R Experienced without a Conscious Choice}

The third major theme identified in this review is related to spiritual and religious experiences perceived as uncontrollable, external and often granted by a Higher Power (Vandecreek and Mottram 2009, 2011; Lynn Gall et al. 2015; Castelli Dransart 2018; Jahn and Spencer-Thomas 2018; Mastrocinque et al. 2018).

Suicide survivors describe these experiences as happening without their conscious choice, for which reason they seem blatant and unexpected, for example:

"I smelt the perfume of a rose and then I found a rose in the street. I took it as a gift, it's not scientific evidence but a strange coincidence; maybe it's an illusion, but what's important it is that that helps you." (Castelli Dransart 2018)

The content of these experiences usually consists of the sense of presence of the deceased, dreams and visions related to the loved one who was lost, and synchronically co-occurring events and signs:

"The family member bereaved by suicide noted that during a subsequent board game, randomly selected letters spelled out a name meaningful to both the bereaved and the deceased. She stated, "[A]nd to me, that was a sign that just could not be, there's no way for that to be explained." Many of these signs were blatant, which one participant noted, "... they smack you in the forehead signs that can't be 'whatever." (Mastrocinque et al. 2018)

Sometimes spiritual experiences come in the form of strong emotional reactions related to specific spaces (like church or cemetery) and events (like public mass):

"It was really a beautiful ceremony, of which I have a good memory, there was a lot of sadness in people, but not in what happened, in the songs, the sermon, it was all hope, many people contributed, we really felt carried" (Castelli Dransart 2018)

Spirituality and religiosity can be spontaneously experienced in the context of relationships with other people (when one is praying together with others or when one is feeling supported emotionally and spiritually by others):

"One person bereaved by suicide shared an emotional story of a police officer who prayed with her, stating, "That was so awesome. And I don't even know, he knew right away. He just knew... He was like an angel that just came down at that minute and it was just strange." (Mastrocinque et al. 2018)

Spiritual/religious experiences can be perceived as helpful and sometimes as hard and confusing, for example:

"These experiences facilitated a grace and peace that transcended the pain of loss." (Jahn and Spencer-Thomas 2018)

"In my dream he was telling me goodbye and telling me why he had to do it so I found some peace in that but at the same time it made me very sad because he was gone." (Jahn and Spencer-Thomas 2018)

They can be seen as unrelated to personal religious beliefs:

"My religious background plays a big role in my continued grief and questioning, but no role in spiritual experiences as described in this study." (Jahn and Spencer-

Thomas 2018) 
In some cases, religious beliefs can help one understand or explain these experiences, for example:

"It kept me from dismissing the experiences \& accepting them \& learning from them." (Jahn and Spencer-Thomas 2018)

Many participants of the studies reviewed shared stories about deepened S/R after a loved one's suicide (Vandecreek and Mottram 2009, 2011; Castelli Dransart 2018; Jahn and Spencer-Thomas 2018; Mastrocinque et al. 2018), which was not always a personal choice but an experience that happened as a gift or help from the Mysterious Other to cope with the devastating tragedy of the loved one's suicide, for example:

"Through all of the pain, it took quite a while for my spiritual life to grow stronger. My faith has helped me grow in many areas and to realise what is REALLY important. It has also helped me make meaning of the loss and honour [his] life and memory." (Jahn and Spencer-Thomas 2018)

Spiritual experiences sometimes functioned as proof for an afterlife, divinity and eternity, which was connected to deepened S/R:

"The experiences have helped me believe even more in a further experience after death." (Jahn and Spencer-Thomas 2018)

To sum up this section, spiritual experiences which occur after a loved one's suicide might be quite common in suicide survivors. They can be overwhelming because they are perceived as external and can be mixed with psychotic symptoms. They can provoke strong emotions and feelings of sadness and grief. However, these experiences are helpful much more often because they evoke hope, a possibility to say goodbye to the loved one or to transform the continuing bond with the deceased. Indeed, these experiences can give comfort and consolation for the bereaved; they occur spontaneously, usually in the forms of deep feelings of connectedness to others or to the Mysterious Other, dreams and visions, sensations and signs. Spiritual experiences can deepen the person's spirituality, religiosity and faith, and add to the creation of a sense of mission and meaning in life. The process, of course, is painful and hard, and, once again, perceived as not consciously chosen.

\subsection{Conscious Reach towards $S / R$ Themes}

The fourth major theme identified during our thematic synthesis of the studies reviewed is in some ways the opposite of the previous theme. This theme is related to the spiritual and/or religious activities that a person consciously chooses to undertake after a loved one's suicide.

One part of this theme is about dealing with S/R-related struggles and conflicts about personal beliefs and/or religious doctrines (Vandecreek and Mottram 2009, 2011; Krysinska et al. 2014; Lynn Gall et al. 2015; Castelli Dransart 2018; Jahn and Spencer-Thomas 2018; Mastrocinque et al. 2018). To people who believe in the good God, the loved one's suicide raises questions about God's responsibility for the suicide. It is not an easy theological question to ask how much free will a person has and how directly God or the Higher Power is involved in peoples' lives, e.g.,:

"For whatever reason, God chose... not to take [the suicide urge] away at this time. I'll never know. But, I also believe He could have stopped the suicide. I believe that my daughter believed in the sovereignty of God and He allowed her to come home at that time. My spirituality is to totally rely on the sovereignty of God and not to question that." (Vandecreek and Mottram 2011)

Sometimes personal religious beliefs must be adjusted or changed to solve questions about the good God and the tragedy of suicide, e.g.,:

"Although rejecting their religion, two individuals continued to investigate different $\mathrm{R} / \mathrm{S}$ traditions in a quest for understanding and meaning. One turned to Wicca/Paganism, embracing a "celebration in life instead of dwelling on death." (Lynn Gall et al. 2015) 
In other cases, thinking about a personally integrated religion's doctrine can provoke fear, guilt, and shame during suicide bereavement, which can make the painful process more difficult:

"I needed to be pardoned through confession to be able to cope with this guilty feeling which fills me. The priest told me something very important: God can forgive you and your wife can forgive you through Christ. And that helped me a lot to receive that absolution, it was another way of re-establishing communication and the relationship, different from spiritualism or esotericism." (Castelli Dransart 2018)

There is also a tendency to devalue the importance of earthly life, which in some ways helps the person to find peace and calmness after a loved one's suicide:

"For me it was like a revelation, this death was part of his journey (...) I believe that we come into this world to learn things and have experiences, once we learn, we change and go off in other directions... I have the conviction that we are ourselves before being born and that we continue on afterwards and so, the importance of this life, which is only one bit, is relative, it is only one bit." (Castelli Dransart 2018)

People who were not religious or spiritual before the loss also experience problems. For example, being non-religious can become an obstacle for getting spiritual, emotional, and practical support after the loss. In some cases, S/R questions and needs occur after suicide despite previous religious beliefs, and spiritual experiences can occur independently from religious beliefs; therefore, the person confronts inner struggles while trying to answer questions about the possibility of the afterlife, the meaning of spiritual experiences (especially the sense of the dead loved one's presence) or a broader meaning of life and death, e.g.,

"At the time I was an atheist like my brother, and then I told myself it wasn't possible, it was unbearable, because he had got to that point; so, there had to be a God once I admitted that there was a presence, something, that lasted for some time. Now, I'm in doubt once again and the Catholic religion doesn't suit me at all, so I've left religion." (Castelli Dransart 2018)

If they do not find solutions to the above described questions and struggles, suicide survivors may experience a spiritual and/or religious crisis. This involves feelings of revolt against God, anger about religion, sadness, loss of faith, disappointment in the idea of God's good will or even the existence of God or the Higher Power, e.g.,:

"I had a strong relationship with Jesus. The only thing I asked for was to help my father and mother to be happy. My father eventually [died by] suicide and my mother[']s life worsened as a result. I discovered that religion was a waste of time." (Jahn and Spencer-Thomas 2018)

Another part of this major theme relates to leaning consciously on spirituality/ religiosity during suicide bereavement. Participants of the studies reviewed share stories about trusting and leaning on faith or God. They pray, engage in dialogue with God, express their sadness and anger, they ask for help and peace and the ability and strength to forgive God or the loved one who died by suicide:

"I realised that if I wanted to continue to have a relationship with God, it was necessary for me to forgive him for what I believed he had done or not done." (Castelli Dransart 2018)

$\mathrm{S} / \mathrm{R}$ sometimes helps to find reconcilement with the haunting unanswerable question of why the loved one died by suicide, for example:

"There is something which escapes, which transcends, a higher force, a destiny, an individual, spiritual path that it is impossible for us to understand until the end." (Castelli Dransart 2018) 
Engaging in personal and religious rituals can also be a conscious way to lean on $S / R$ during bereavement. Suicide survivors sometimes find inner peace and comfort during masses, in prayers or meditation, for example:

"I prayed to God... you take the person you're concerned about, and you wrap them in something. And I chose a flannel blanket... this was before he [her son] died. And I wrapped him in the flannel blanket (crying) and I handed him to God... and... I said, "You guide." So when [my son] died I think God said it was OK." (Lynn Gall et al. 2015)

Conscious involvement in $S / R$ can condition the experience of deepened $S / R$, which might carefully be considered a transformational part of the traumatic suicidal loss:

"It deepened my understanding of God and the way He works in our lives and how He uses everything in our life to develop us. I knew that because the Bible tells us that, but I didn't know it experientially... Now I get it. And that's how I felt. I felt like I finally really got it. And in spite of how awful this has been, God has been faithful to me and, like I say, ... it just deepened my faith in God." (Vandecreek and Mottram 2011)

Overall, people bereaved by suicide can consciously turn to S/R. Sometimes they experience inner conflicts and struggles and think a lot about the meaning of suicide, the Higher Power and its involvement and responsibility for suicide and the laws of God's justice. These struggles relate to spiritual/religious crises that might happen quite often among suicide survivors. S/R can also function as a resource, a dimension to lean on during bereavement after suicide. Praying and engaging in rituals can give comfort, deepen faith and function as a way to find strength when coping with painful feelings of grief.

\subsection{Not Relating to $S / R$ Themes during Suicide Bereavement}

Spirituality and/or religiosity during suicide bereavement are not necessarily experienced or contemplated. Even if interpreted as spiritual experiences elsewhere, the same experiences (e.g., the sense of presence of the loved one who died) sometimes are perceived as psychological mechanisms (Jahn and Spencer-Thomas 2018). The suicide of the loved one in some cases does not influence $S / R$, especially if the bereaved person is not religious and the questions of S/R after the loved one's death do not turn up (Castelli Dransart 2018; Jahn and Spencer-Thomas 2018).

\section{Discussion}

This review has aimed to provide a synthesis of qualitative studies on spirituality and/or religiosity during suicide bereavement. The findings show the complexity of the role of $S / R$ in suicide bereavement. $S / R$ sometimes functions as a supportive resource, and at other times as a complicated part of the bereavement process. An important and distinct topic related to S/R during suicide bereavement involves the suicide survivors' need to be helped and supported by the religious community, which is opposite to the fear and experiences of being judged by members of the religious community. S/R creates continuing bonds through beliefs in the afterlife, rituals, and the sense of the loved one's presence. Suicide survivors sometimes do not feel having a conscious choice to experience $\mathrm{S} / \mathrm{R}$, experiences that are powerful and might deepen spirituality. On the other hand, some suicide survivors experience a major spiritual crisis. Others consciously reach towards $S / R$ and lean on God or the Higher Power during bereavement. Lastly, some suicide survivors do not relate to $S / R$ themes during bereavement and interpret experiences similar to $S / R$ as psychological mechanisms. We will discuss our main findings in the following sections.

\subsection{The Need to Be Helped by the Religious Community without Being Judged}

The religious community, including religious leaders and other community members, can help suicide survivors in practical, emotional, and spiritual ways. Many participants of the studies reviewed herein received support from religious communities and were thank- 
ful for it. Yet, there were stories about judgmental attitudes and inadequate behaviours on the part of religious communities, which upset suicide survivors. People bereaved by suicide experience stigmatisation because of the cause of death of their loved one (Pompili et al. 2013) and sometimes are afraid to be judged (Pompili et al. 2013; Sheehan et al. 2018). If a person is afraid to talk about their loss, isolation and loneliness can contribute to a harder grief process (Peters et al. 2016). It must be noted that if the community is able to adjust to suicide survivors' needs, this can be an effective resource to help the bereaved person in many ways and can even take part in changing the stigmatising attitudes towards suicide and suicide survivors. However, if the community holds stigmatising and judgmental views and acts on them, the damage for suicide survivors might be severe.

Why do religious communities and themes of stigmatisation go hand in hand so often? Stigmatisation of suicide is rooted in the collective and religion-related attitudes that suicide is a mortal sin. In Europe this idea spread in the 17th century and was related to the Christian doctrine blaming the deceased for choosing to die by suicide (Solano et al. 2018). In the middle of the 20th century, the Christian doctrine was adjusted and the attitude to suicide changed such that suicide is now viewed as a partly unconscious act induced by psychological problems, which is not a mortal sin (Gearing and Alonzo 2018). As the Church is a gigantic institution, it is not surprising that the doctrine might be interpreted differently in different communities. This review concerns almost entirely Christian samples because in the studies reviewed participants were mostly Christians. Other religions might have different and even more judgmental views towards suicide. A suicide survivor surrounded by cultural, religious, and personal views of other people towards suicide might find themselves alone with the fear for the fate of the deceased and with their pain related to the process of bereavement. This indicates how detrimental the consequences of condemning the person who died by suicide may be.

\subsection{S/R-Related Experience of the Deceased as a Continuing to Exist Figure}

Our review discloses the role of $S / R$ in suicide survivors' explanations, perceptions, and experiences of the loved one's fate after death and continuing bonds between the bereaved and the deceased.

The idea of an afterlife might give the bereaved person comfort as well as make them concerned and distressed. If the bereaved person believes in a positive afterlife in which reunion with the deceased is possible, these beliefs might relate to a more positive adjustment during general grief (Wortmann and Park 2008; Lichtenthal et al. 2013). The fear of death and temporality is countered by the hope for an afterlife (Stelzer et al. 2020). But suicide as the cause of death triggers concerns about the journey of the loved one's soul. Suicide survivors sometimes find themselves concerned about the deceased's status in God's eyes or in the process of reincarnation. The concept of the afterlife and concerns about it are closely related to religious attitudes about suicide and it seems that such thoughts and concerns are pertinent not only to people who are strong believers in one religion or another. These concepts might be rooted in the adopted cultural or traditional theories about what happens after death and about suicide as a mortal sin. The belief that the loved one is not completely gone might be comforting and needful for the bereaved person. But concerns about a bad afterlife provoke fear and anxiety.

Importantly, concerns about the afterlife in people bereaved by suicide may be alleviated by religious and spiritual practices and rituals. The farewell ritual or praying immediately after the suicide is seen as a first step in helping the deceased's soul, and, psychologically speaking, also in the beginning of transforming the relationship with the deceased through symbolic methods (rituals). The importance of personally meaningful rituals in continuing bonds and the bereavement process might be related to their culturally rooted, experiential, and emotional nature (Scrutton 2017). Facing death usually means facing something uncontrollable and scary, therefore from the rational perspective, the person is not capable of preventing anything. But from the spiritual or religious perspective, the person can carry out rituals and prayers to accompany the loved one on the way to the 
transcendental realm. $\mathrm{S} / \mathrm{R}$ in this case provides a means to feel at least a bit of agency and hope in an unchangeable situation.

The loved one's existence after death and the continuing bond are often not only thought about but also experienced as a sense of presence of the deceased. These experiences can come spontaneously as visions, dreams, or signs, or be induced by reaching out to the deceased, for example, through mediums. They are usually described as very obvious and therefore tend to be perceived as a true, real connection with the loved one and as proof of existence after death. The experiential nature of the sense of presence seems to be closely related to the experiential nature of spirituality and connectedness to something that cannot be seen but can be sensed (Tacey 2004; Pargament 2007). In the Jungian approach, visions and dreams come not only because of the repressed memories, but also as a message of potentiality. It is important how a person interprets the message and how they act on it (Johnson 1986). People bereaved by suicide sometimes find this potentiality aspect in the sense of presence of the deceased, and, rationally or intuitively, make hopeful conclusions about the afterlife and a lasting relationship with the deceased, which can ease the pain of the loss and help with finding meaning (Neimeyer et al. 2006; Steffen and Coyle 2011) and integrating the loss (Jordan and McGann 2017). Although these experiences of the presence of the deceased might be viewed as delusional by many theoretical perspectives (Ratcliffe 2020), empirical studies and our review bespeak the healing potential of the sense of presence. Beliefs and concerns about the afterlife, rituals as a way to participate in the deceased person's afterlife, and the sense of presence of the deceased help to transform and hold on to continuing bonds with the loved one, which is important for the whole bereavement process (Klass and Steffen 2018). The striking moments of the sense of presence tend to become rarer with time, which marks transformations of the bond during the process of grief.

\subsection{S/R Experienced without a Conscious Choice}

Spiritual and religious experiences are sometimes perceived by suicide survivors without a conscious choice. To our knowledge, this is a new, distinct, and important finding in the research field of suicide bereavement. The perceived external nature of spiritual experiences involves not only the above discussed sense of presence of the deceased, but also the sense of connectedness to the Mysterious Other or other people, feelings of grace, gratitude, or deep relief during grief. These feelings and perceptions can result in deepened spirituality and a sense of mission in life.

The deepened spirituality can be explained by the concept of post-traumatic growth, which is defined as a positive change that occurs after a traumatic and painful event and manifests in a variety of ways, including an increased appreciation of life in general, more meaningful interpersonal relationships, an increased sense of personal strength, changed priorities, and a richer existential and spiritual life (Tedeschi and Calhoun 2004). Importantly, positive religious coping, religious openness, readiness to face existential questions, religious participation and intrinsic religiousness are associated with stronger post-traumatic growth (Shaw et al. 2005). With regard to people bereaved by suicide, post-traumatic growth can be experienced after losing a loved one to suicide (Feigelman et al. 2009; Moore et al. 2015), but the positive outcomes of the traumatic loss do not denote the absence of distress (Smith et al. 2011). Deepened spirituality might be the result of provoked post-traumatic growth after suicide loss, but it does not necessarily change the pain and feelings of despair.

An uneasy question that perhaps transgresses the limits of psychology is why and how these S/R experiences happen in the first place during suicide bereavement. On the one hand, this can be explained as a psychological mechanism that helps one to cope with deeply painful feelings. The positive, calming, and soothing emotional experiences provide hope and comfort and remind one that there is not only suffering in life, thereby giving hope to the bereaved person. From the Jungian point of view, a traumatising loss and grief for at least some time weaken the ego boundaries and defences, which elicits an 
intensified connection with the unconscious and inflation of the ego (Kast 1993). Therefore, metaphorically speaking, the person meets both demons and angels, or experiences both hell and Heaven, which opens the gates to potential growth as well as regression in many domains. In our current research, we will not speculate about theological explanations for $\mathrm{S} / \mathrm{R}$ experiences undergone without a conscious choice.

\subsection{Conscious Reach towards $S / R$ Themes}

People bereaved by suicide might consciously lean on the Sacred to find strength, hope and support. Religions suggest various methods for how to do that, such as praying, talking to God, meditating, and engaging in rituals. This could be called positive religious coping, which in some studies has been found to potentially lead to better coping with the loss (Becker et al. 2007; Wortmann and Park 2008). Active involvement in praying and asking God for help and strength might give the bereaved person a feeling of control in their life, which might be needed in the context of intensive feelings after the loss of a loved one to suicide. In the Jungian approach, there is an explanation (albeit theoretical rather than scientifically proven) why actively and consciously leaning on the Sacred is not a one-way relationship. The idea that the person's ego can have an at least partially conscious relationship with the unconscious means that if the person consciously starts a dialogue with the unconscious, the unconscious will 'reveal itself' and respond through meaningful dreams and visions (Johnson 1986). To sum up, S/R can be a semi-consciously chosen resource during suicide bereavement.

Conscious reach towards $S / R$ themes is also related to a spiritual/religious crisis after loss. People bereaved by suicide try to explain God's involvement in the act of suicide, and why He did not prevent the suicide and all the suffering, to themselves. Disappointment in the good and just God provokes anger and revolt. Some people engage in a dialogue with God and express their anger in prayers, others lose their faith. The spiritual and religious crisis can be eased by finding answers to responsibility-related questions or by adjusting personal beliefs. If previously religious people lose their faith after the loved one's suicide, their sense of meaning can be profoundly shaken. The spiritual/religious crisis can be called negative spiritual/religious coping and is related to prolonged grief disorder, negative bereavement outcomes and more severe depression following a violent death of the loved one (Heeke et al. 2017). The disturbed or even lost relationship with one's previous religion or spiritual beliefs can be interpreted as a disturbed connection with the Self as a guiding part of the person's psyche that gives meaning, purpose, feelings of connectedness to the Universe and others, trust and hope (Jung [1938] 1960; Tacey 2004). Therefore, the spiritual/religious crisis that follows the loved one's suicide might seriously harden the bereavement process.

\subsection{Limitations and Further Research}

The findings of this review are not devoid of limitations. The search for potential studies related to $S / R$ was conducted in only three databases and only studies published in English were included in the review. A greater number of databases and a wider pool of studies (for example, those published not only in English, not only in peer-reviewed articles but also doctoral theses) might extend the scope of studies for such a review. Validation of the major themes and subthemes and synthesis of the qualitative data were based only on the results sections in the original papers and might have been influenced by the reviewers' attitudes towards $S / R$ and suicide bereavement, theoretical knowledge about grief and personal/clinical experience and/or personal feelings about the theme. The initial coding might have been influenced by the fact that none of the reviewers are native speakers of English, which could have affected their understanding of the meaning of the texts. We hope that some of the potential errors were prevented by the very process of reviewing the studies, which involved three reviewers, double initial coding and discussions. Another limitation was that most participants in the studies included in the review were female and from Christian communities. 
Despite these limitations, this review brings important insights into the role of $S / R$ during suicide bereavement and is likely to contribute to a deeper understanding of bereavement after suicide and $S / R$. To our knowledge, this is the first systematic review of qualitative studies of $S / R$ during suicide bereavement. The review provides synthesised themes about experiences of suicide survivors, which broadens the understanding of what problems related to $S / R$ suicide survivors face and what the main relevant components of survivors' relationships with religious communities are, how $S / R$ can function in the continuing bonds with the deceased during suicide bereavement, how S/R can be experienced and perceived after a loved one's suicide and how suicide survivors lean on $S / R$ as a resource.

Our findings open new directions for further research. Research of religious communities and the clergy should involve studies about attitudes towards suicide, aspects of working with people bereaved by suicide and the clergy's readiness to provide support for suicide survivors. Future studies might explore the roots and varieties of the rituals people use during suicide bereavement and functions of experiential connections with the deceased loved one after suicide. Researchers should also explore the circumstances conducive of spiritual experiences and positive and negative outcomes of the ambivalent experience of suffering and inspiration. Future research should widen the understanding of a long-term relationship with $S / R$ in people bereaved by suicide and try to answer what happens if their faith is lost, whether it can be repaired and how. Quantitative studies should investigate the correlates and factors related to belief in the afterlife, rituals, religiosity, spirituality and bereavement adjustment. New studies should involve more males and more diversely affiliated or secular participants.

\subsection{Guidelines for Spiritual/Religious Leaders and Mental Health Professionals}

The findings of our review provide useful information for the clergy and mental health professionals who support and work with suicide survivors.

First, the clergy and spiritual leaders should cautiously examine and reflect on personal and doctrinal attitudes towards suicide. The theme of suicide should be discussed carefully in religious communities, and communication with people bereaved by suicide should be informed by psychological knowledge of suicidology. Spiritual/religious crises that individuals experience after their loved one's suicide should be treated in light of their psychological consequences, and respectful ways must be found to help and support people who have lost their faith.

Second, mental health professionals who work with suicide survivors should not be afraid to encourage their inner dialogues with God and request divine help if the suicide survivor believes in something bigger. It might also be helpful to involve personal rituals into the process of supporting the survivor. In addition, we see the importance of normalising (Jahn and Spencer-Thomas 2014) and helping to derive meaning from spiritual experiences (Steffen and Coyle 2010) when working with suicide survivors.

Third, with regard to the delicate state of the potentially weakened ego after the loss, we encourage practitioners to work on strengthening the client's ego, which helps to withstand, reflect and derive meaning from the contents of the unconscious. Acceptance, withstanding and normalising of these completely opposite experiences is also important.

Fourth, mental health professionals should consider the destructive nature of spiritual/religious crises experienced by suicide survivors and encourage them to at least talk about the issue and reflect on it.

Lastly, not all the people bereaved by suicide connect with religious/spiritual themes. The process of bereavement is complex and subjective and it is normal not to experience anything related to $S / R$. When working with suicide survivors, $S / R$ themes should only be touched upon if the survivor wants to talk about and reflect on them. 


\section{Conclusions}

The human potential to search for the Sacred (Jung [1938] 1960; Pargament 2007; Tacey 2004) might be connected to the human potential to find ways to live through the tragedy of a loved one's suicide. Bereavement after suicide is a hard and long-lasting experience that might trigger spiritual/religious concerns. Religious communities as representations of religion and faith can be very helpful in supporting suicide survivors, but the stigma of suicide estranges a suicide survivor from the potential help they could get. S/R can be a helpful source for transforming the relationship with the deceased and a way to cope with the loss. However, faith and beliefs can be shaken by the loss and S/R can start to function as a hindrance in people bereaved by suicide. There is too little research about $S / R$ in suicide bereavement given the importance of the subject of the current review. To deepen and widen our understanding, we suggest studying suicide bereavement and S/R from psychological, theological, and/or philosophical standpoints. We also advise practitioners to bravely talk about themes related to $S / R$ with suicide survivors and provide them with adequate help if such help is needed.

Author Contributions: Conceptualization, A.A.Č.; methodology, A.A.Č., B.P. and K.S.; writingoriginal draft preparation, A.A.Č.; writing—review and editing, A.A.Č., D.G., P.S.; supervision, D.G., P.S. All authors have read and agreed to the published version of the manuscript.

Funding: This research received no external funding.

Institutional Review Board Statement: Not applicable.

Informed Consent Statement: Not applicable.

Data Availability Statement: Data available in a publicly accessible repository.

Acknowledgments: The article's text was edited by Simona Kontrimienè.

Conflicts of Interest: The authors declare no conflict of interest.

\section{References}

Agerbo, Esben. 2005. Midlife suicide risk, partner's psychiatric illness, spouse and child bereavement by suicide or other modes of death: A gender specific study. Journal of Epidemiology \& Community Health 59: 407-12.

Andriessen, Karl, Karolina Krysinska, Nicole T. M. Hill, Lennart Reifels, Jo Robinson, Nicola Reavley, and Jane Pirkis. 2019. Effectiveness of interventions for people bereaved through suicide: A systematic review of controlled studies of grief, psychosocial and suiciderelated outcomes. BMC Psychiatry 19: 49. [CrossRef] [PubMed]

Becker, Gerhild, Carola J. Xander, Hubert E. Blum, Johannes Lutterbach, Felix Momm, Marjolein Gysels, and Irene J. Higginson. 2007. Do Religious or Spiritual Beliefs Influence Bereavement? A Systematic Review. Palliative Medicine 21: 207-17. [CrossRef]

Bellini, Samantha, Denise Erbuto, Karl Andriessen, Mariantonietta Milelli, Marco Innamorati, David Lester, Gaia Sampogna, Andrea Fiorillo, and Maurizio Pompili. 2018. Depression, hopelessness, and complicated grief in survivors of suicide. Frontiers in Psychology 9: 198. [CrossRef] [PubMed]

Castelli Dransart, Dolores Angela. 2018. Spiritual and religious issues in the aftermath of suicide. Religions 9: 153. [CrossRef]

Cerel, Julie, John L. McIntosh, Robert A. Neimeyer, Myfanwy Maple, and Doreen Marshall. 2014. The continuum of "survivorship": Definitional issues in the aftermath of suicide. Suicide and Life-Threatening Behavior 44: 591-600. [CrossRef]

Colucci, Erminia. 2008. Recognizing spirituality in the assessment and prevention of suicidal behaviour. World Cultural Psychiatry Research Review 3: 77-95.

Erlangsen, Annette, Bo Runeson, James M. Bolton, Holly C. Wilcox, Julie L. Forman, Jesper Krogh, M. Katherine Shear, Merete Nordentoft, and Yeates Conwell. 2017. Association between spousal suicide and mental, physical, and social health outcomes: A longitudinal and nationwide register-based study. JAMA Psychiatry 74: 456-64. [CrossRef]

Farberow, Norman L., Dolores Gallagher-Thompson, Michael Gilewski, and Larry Thompson. 1992. The Role of Social Supports in the Bereavement Process of Surviving Spouses of Suicide and Natural Deaths. Suicide and Life-Threatening Behavior 22: 107-24. [CrossRef]

Feigelman, William, John R. Jordan, and Bernard S. Gorman. 2009. Personal growth after a suicide loss: Cross-sectional findings suggest growth after loss may be associated with better mental health among survivors. OMEGA-Journal of Death and Dying 59: 181-202. [CrossRef]

Gearing, Robin Edward, and Dana Alonzo. 2018. Religion and suicide: New findings. Journal of Religion and Health 57: 2478-99. [CrossRef] 
Hai, Audrey Hang, Jennifer Currin-McCulloch, Cynthia Franklin, and Allan Hugh Cole Jr. 2018. Spirituality/religiosity's influence on college students' adjustment to bereavement: A systematic review. Death Studies 42: 513-20. [CrossRef] [PubMed]

Hanschmidt, Franz, Franziska Lehnig, Steffi G. Riedel-Heller, and Anette Kersting. 2016. The stigma of suicide survivorship and related consequences-A systematic review. PLoS ONE 11: e0162688. [CrossRef] [PubMed]

Heeke, Carina, Christina Kampisiou, Helen Niemeyer, and Christine Knaevelsrud. 2017. A systematic review and meta-analysis of correlates of prolonged grief disorder in adults exposed to violent loss. European Journal of Psychotraumatology 8: 1583524. [CrossRef]

Hjelmeland, Heidi, and Birthe Loa Knizek. 2010. Why we need qualitative research in suicidology. Suicide and Life-Threatening Behavior 40: 74-80. [CrossRef] [PubMed]

Honeycutt, Amy, and Regina Trudy Praetorius. 2016. Survivors of suicide: Who they are and how do they heal? Illness, Crisis $\mathcal{E}$ Loss 24: 103-18. [CrossRef]

Jahn, Danielle R., and Sally Spencer-Thomas. 2014. Continuing Bonds through after-Death Spiritual Experiences in Individuals Bereaved by Suicide. Journal of Spirituality in Mental Health 16: 311-24. [CrossRef]

Jahn, Danielle R., and Sally Spencer-Thomas. 2018. A Qualitative Examination of Continuing Bonds through Spiritual Experiences in Individuals Bereaved by Suicide. Religions 9: 248. [CrossRef]

JBI. 2020. Critical Appraisal Checklist for Qualitative Studies. Available online: https://jbi.global/critical-appraisal-tools (accessed on 26 June 2021).

Johnson, Robert A. 1986. Inner Work. San Francisco: Harper San Francisco.

Jordan, John R. 2001. Is suicide bereavement different? A reassessment of the literature. Suicide and Life-Threatening Behavior 31: 91102. Available online: https:/ / onlinelibrary.wiley.com/doi/pdf/10.1521/suli.31.1.91.21310?casa_token=mCuuR7SbKIAAAAA: wVS8peEcnM_hGIqSL1J2wA21tGlQEluDR083Tku6DCpDZt8sZ4youqpu9qYWqH9GzSJcnMy6LsG (accessed on 26 June 2021). [CrossRef]

Jordan, John R. 2017. Postvention is prevention-The case for suicide postvention. Death Studies 41: 614-21. [CrossRef]

Jordan, John R., and Vanessa McGann. 2017. Clinical work with suicide loss survivors: Implications of the US postvention guidelines. Death Studies 41: 659-72. [CrossRef]

Jung, Carl Gustav. 1960. Psychology and Religion. London: Yale University Press. First published 1938.

Kast, Verena. 1993. Time to Mourn: Growing through the Grief Process. Einsiedeln: Daimon Verlag.

Klass, Dennis, and Edith Maria Steffen. 2018. Continuing Bonds in Bereavement. New Directions for Research and Practice. New York: Routledge/Tailor \& Frances Group.

Krysinska, Karolina, Danielle R. Jahn, Sally Spencer-Thomas, and Karl Andriessen. 2017. The Roles of Religion and Spirituality in Suicide Bereavement and Postvention. In Postvention in Action: The International Handbook of Suicide Bereavement Support, 1st ed. Edited by Karl Andriessen, Karolina Krysinska and T. Grad Onja. Boston: Hogrefe, pp. 186-97. ISBN 978-0-88937-493-5.

Krysinska, Karolina, Karl Andriessen, and Jozef Corveleyn. 2014. Religion and Spirituality in Online Suicide Bereavement: An Analysis of Online Memorials. Crisis 35: 349-56. [CrossRef]

Levi-Belz, Yossi. 2017. Relationship with the deceased as facilitator of posttraumatic growth among suicide-loss survivors. Death Studies 41: 376-84. [CrossRef]

Lichtenthal, Wendy G., Robert A. Neimeyer, Joseph M. Currier, Kailey Roberts, and Nancy Jordan. 2013. Cause of Death and the Quest for Meaning after the Loss of a Child. Death Studies 37: 311-42. [CrossRef]

Linde, Katja, Julia Treml, Jana Steinig, Michaela Nagl, and Anette Kersting. 2017. Grief interventions for people bereaved by suicide: A systematic review. PLoS ONE 12: e0179496. [CrossRef] [PubMed]

Lynn Gall, Terry, Jesse Henneberry, and Melissa Eyre. 2015. Spiritual beliefs and meaning-making within the context of suicide bereavement. Journal for the Study of Spirituality 5: 98-112. [CrossRef]

Maple, Myfanwy, Julie Cerel, Rebecca Sanford, Tania Pearce, and Jack Jordan. 2017. Is exposure to suicide beyond kin associated with risk for suicidal behavior? A systematic review of the evidence. Suicide and Life-Threatening Behavior 47: 461-74. [CrossRef] [PubMed]

Mastrocinque, Jeanna M., Taylor Hartwell, Jed W. Metzger, Renae Carapella-Johnson, Peter K. Navratil, and Catherine Cerulli. 2018. Spirituality and religion after homicide and suicide: Families and friends tell their stories. Homicide Studies 24: 107-26. [CrossRef]

Moore, Melinda M., Julie Cerel, and David A. Jobes. 2015. Fruits of trauma? Posttraumatic growth among suicide-bereaved parents. Crisis: The Journal of Crisis Intervention and Suicide Prevention 36: 241. [CrossRef] [PubMed]

Murphy, Shirley A., and L. Clark Johnson. 2003. Finding Meaning in a Child's Violent Death: A Five-Year Prospective Analysis of Parents' Personal Narratives and Empirical Data. Death Studies 27: 381-404. [CrossRef]

Neimeyer, Robert A., Scott A. Baldwin, and James Gillies. 2006. Continuing bonds and reconstructing meaning: Mitigating complications in bereavement. Death Studies 30: 715-38. [CrossRef]

Oexle, Nathalie, William Feigelman, and Lindsay Sheehan. 2020. Perceived suicide stigma, secrecy about suicide loss and mental health outcomes. Death Studies 44: 248-55. [CrossRef]

Page, Matthew J., Joanne E. McKenzie, Patrick M. Bossuyt, Isabelle Boutron, Tammy C. Hoffmann, Cynthia D. Mulrow, Larissa Shamseer, Jennifer M. Tetzlaff, Elie A. Akl, Sue E. Brennan, and et al. 2021. The PRISMA 2020 statement: An updated guideline for reporting systematic reviews. BMJ 2021: 372. [CrossRef]

Pargament, Kenneth I. 2007. Spiritually Integrated Psychotherapy: Understanding and Addressing the Sacred. New York: Guilford Press. 
Pargament, Kenneth I., and James W. Lomax. 2013. Understanding and addressing religion among people with mental illness. World Psychiatry 12: 26-32. [CrossRef]

Peters, Kath, Colleen Cunningham, Gillian Murphy, and Debra Jackson. 2016. 'People look down on you when you tell them how he died': Qualitative insights into stigma as experienced by suicide survivors. International Journal of Mental Health Nursing 25: 251-57. [CrossRef]

Pompili, Maurizio, Amresh Shrivastava, Gianluca Serafini, Marco Innamorati, Mariantonietta Milelli, Denise Erbuto, Federica Ricci, Dorian A. Lamis, Paolo Scocco, Mario Amore, and et al. 2013. Bereavement after the suicide of a significant other. Indian Journal of Psychiatry 55: 256. [CrossRef]

Ratcliffe, Matthew. 2020. Sensed presence without sensory qualities: A phenomenological study of bereavement hallucinations. Phenomenology and the Cognitive Sciences 20: 601-16. [CrossRef]

Saini, Michael, and Aron Shlonsky. 2012. Systematic Synthesis of Qualitative Research. New York: Oxford University Press.

Sas, Corina, and Alina Coman. 2016. Designing personal grief rituals: An analysis of symbolic objects and actions. Death Studies 40: 558-69. [CrossRef] [PubMed]

Scrutton, Anastasia Philippa. 2017. Grief, ritual and experiential knowledge: A philosophical perspective. In Continuing Bonds in Bereavement. Edited by Dennis Klass and Edith Maria Steffen. New York: Routledge/Taylor and Francis Group, pp. $214-26$.

Shaw, Annick, Stephen Joseph, and P. Alex Linley. 2005. Religion, spirituality, and posttraumatic growth: A systematic review. Mental Health, Religion \& Culture 8: 1-11. [CrossRef]

Sheehan, Lindsay, Patrick W. Corrigan, Maya A. Al-Khouja, Stanley A. Lewy, Deborah R. Major, Jessica Mead, Megghun Redmon, Charles T. Rubey, and Stephanie Weber. 2018. Behind closed doors: The stigma of suicide loss survivors. OMEGA-Journal of Death and Dying 77: 330-49. [CrossRef] [PubMed]

Shields, Chris, Michele Kavanagh, and Kate Russo. 2017. A qualitative systematic review of the bereavement process following suicide. OMEGA-Journal of Death and Dying 74: 426-454. [CrossRef]

Smith, Angela, Stephen Joseph, and Roshan Das Nair. 2011. An interpretative phenomenological analysis of posttraumatic growth in adults bereaved by suicide. Journal of Loss and Trauma 16: 413-30. [CrossRef]

Solano, P., E. Pizzorno, M. Pompili, G. Serafini, and M. Amore. 2018. Conceptualizations of suicide through time and socio-economic factors: A historical mini-review. Irish Journal of Psychological Medicine 35: 75-86. [CrossRef]

Spillane, Ailbhe, Celine Larkin, Paul Corcoran, Karen Matvienko-Sikar, Fiona Riordan, and Ella Arensman. 2017. Physical and psychosomatic health outcomes in people bereaved by suicide compared to people bereaved by other modes of death: A systematic review. BMC Public Health 17: 939. [CrossRef]

Steffen, Edith M., and Adrian Coyle. 2010. Can 'Sense of Presence' experiences in bereavement be conceptualized as spiritual phenomena? Mental Health, Religion and Culture 13: 273-91. [CrossRef]

Steffen, Edith, and Adrian Coyle. 2011. Sense of Presence Experiences and Meaning-Making in Bereavement: A Qualitative Analysis. Death Studies 7: 579-609. [CrossRef]

Stelzer, Eva-Maria, Roman Palitsky, Emily N. Hernandez, Eli G. Ramirez, and Mary-Frances O'Connor. 2020. The role of personal and communal religiosity in the context of bereavement. Journal of Prevention E Intervention in the Community 48: 64-80. [CrossRef]

Stroebe, Margaret, Henk Schut, and Kathrin Boerner. 2010. Continuing bonds in adaptation to bereavement: Toward theoretical integration. Clinical Psychology Review 30: 259-68. [CrossRef] [PubMed]

Tacey, David. 2004. The Spirituality Revolution: The Emergence of Contemporary Spirituality. New York: Brunner-Routledge/Tailor \& Francis Group.

Tedeschi, Richard G., and Lawrence Calhoun. 2004. Posttraumatic growth: A new perspective on psychotraumatology. Psychiatric Times 21: 58-60. Available online: https://www.bu.edu/wheelock/files/2018/05/Article-Tedeschi-and-Lawrence-CalhounPosttraumatic-Growth-2014.pdf (accessed on 26 June 2021).

Thomas, James, and Angela Harden. 2008. Methods for the thematic synthesis of qualitative research in systematic reviews. BMC Medical Research Methodology 8: 45. Available online: https://bmcmedresmethodol.biomedcentral.com/articles/10.1186/1471-2 288-8-45 (accessed on 26 June 2021). [CrossRef]

Tong, Allison, Kate Flemming, Elizabeth McInnes, Sandy Oliver, and Jonathan Craig. 2012. Enhancing transparency in reporting the synthesis of qualitative research: ENTREQ. BMC Medical Research Methodology 12: 181. Available online: http://www. biomedcentral.com/1471-2288/12/181 (accessed on 26 June 2021). [CrossRef] [PubMed]

Vandecreek, Larry, and Kenneth Mottram. 2009. The Religious Life during Suicide Bereavement: A Description. Death Studies 33: 741-61. [CrossRef] [PubMed]

Vandecreek, Larry, and Kenneth Mottram. 2011. The perceived roles of God during suicide bereavement. Journal of Psychology and Theology 39: 155-162. [CrossRef]

WHO (World Health Organization). 2021. “Suicide.” World Health Organization Media Centre. Available online: http:/ /www.who. int/mediacentre/factsheets/fs398/en/ (accessed on 27 May 2021).

Wortmann, Jennifer H., and Crystal L. Park. 2008. Religion and Spirituality in Adjustment Following Bereavement: An Integrative Review. Death Studies 32: 703-36. [CrossRef]

Young, Ilanit Tal, Alana Iglewicz, Danielle Glorioso, Nicole Lanouette, Kathryn Seay, Manjusha Ilapakurti, and Sidney Zisook. 2012. Suicide bereavement and complicated grief. Dialogues in Clinical Neuroscience 14: 177. Available online: https://www.ncbi.nlm. nih.gov / pmc/articles/PMC3384446/ (accessed on 26 June 2021). 